\title{
Effect of fiber loading on mechanical properties of oil palm frond/urea formaldehyde (OPF/UF) composite
}

\author{
Beatrice Dimah Richard ${ }^{1, *}$, Azizah Wahi ${ }^{1}$, Rozie Nani ${ }^{2}$, Elisha Iling ${ }^{1}$, Shahril \\ Osman ${ }^{1}$, Dayang Siti Hazimmah Ali ${ }^{1}$
}

${ }^{1}$ School of Engineering and Technology, University College of Technology Sarawak, Sibu, Sarawak, 96000, MALAYSIA.

${ }^{2}$ Pusat Pengajian Kejuruteraan Pembuatan, Universiti Malaysia Perlis, Kampus Pauh Putra, Arau, Perlis, 02600, MALAYSIA.

*Corresponding Author

DOI: https://doi.org/10.30880/ijie.2019.11.07.016

Received 09 October 2019; Accepted 25 October 2019; Available online 15 November 2019

\begin{abstract}
Research on composite have been widely done throughout the world. Incorporation of reinforcing materials into matrix can one day replace the use of conventional materials such as polymers, metals, ceramics and woods. In this research, a composite made of oil palm frond fiber and urea formaldehyde is fabricated. As oil palm frond fiber can be obtained in great amount due to high amount of wastage generated, composite can be a way to reduce this wastage. There were two different type of fiber loading prepared which were $40 \%$ and $50 \%$. The fiber and UF were mixed until homogenous. It is then placed into the hot press machine to undergo hot press process. After the fabrication, the mechanical properties of the composite will be tested and observed. The mechanical test includes flexural and tensile test. Both tests are done in accordance to the ASTM standard which are ASTM D-790 and ASTM D-638. The morphological characteristic of the composite will also be observed in this study. The results showed that the composite with higher fiber loading, which is $50 \%$, have better mechanical properties. The composite with $50 \%$ of fiber has a flexural strength of $1.4306 \mathrm{MPa}$, a modulus of elasticity (MOE) of 1248.9516 $\mathrm{MPa}$ and a tensile strength of $3.874 \mathrm{MPa}$. These composites can be used as an alternative for wood and automotive application.
\end{abstract}

Keywords: Oil palm frond fiber, urea formaldehyde, composite, fiber loading, mechanical properties

\section{Introduction}

As the world is advancing so fast, countries or nations are competing with each other on their technology [1]. Research and development on new products or materials are widely being done around the world. Slowly, conventional materials will be replaced by composites. Conventional materials include polymers, metals, ceramics and woods [2]. Composite consists of two constituents which are the matrix and the reinforcing materials [3]. As composites exhibit anisotropic behavior, they will have different properties when force or stress is applied from different directions [4]. In this study, fiber will be used as the reinforcing material. It can contribute to the strength and stiffness of the composites. Compare to the matrix, fiber carries majority of the load [1]. There are various type of fibers, for example, carbon, aramid, glass and natural fibers [1]. In this study, natural fiber will be used. Natural fiber possesses its own natural characteristics; thus, it is unique [5]. Some of the properties of natural fibers include renewable source, biodegradable and light weight [6]. Natural fiber also uses $60 \%$ less energy in the production process compare to glass fiber [7]. There are few categories under natural fiber, which are plant fibers, animal fibers and mineral fibers [8]. 

Oil palm business has contributed a lot to the agriculture and economy of the country. However, when the production of oil palm products increases, the wastage also increases significantly. When it is not handled properly, it could affect the environment. The oil palm tree has many different parts, for example empty fruit bunch, fresh fruit bunch, oil palm frond, oil palm trunk and so on. From all of these parts, the one with the most amount of waste generated is oil palm frond where they contribute to $70 \%$ of the waste [9]. By the year 2020, the OPF waste generated may reach to 110 million tons [10]. The peak season of cutting the oil palm frond is during the pruning of oil palm tree and harvesting period [11]. The objective of this study is to study the effect of fiber loading on the mechanical properties of oil palm frond and urea-formaldehyde (OPF/UF) composite. In this study, the reinforcing fiber used is the oil palm frond fiber. Oil palm frond fiber consists of 40 to $50 \%$ cellulose, 34 to $38 \%$ hemicellulose, 80 to $84 \%$ holocellulose, 20 to $21 \%$ lignin and $4.5 \%$ of extractive [12]. During the harvesting or pruning period, oil palm frond can be obtained easily and in great amount. Thus, by incorporating it into composites as a reinforcing material, oil palm frond waste can be converted into something useful and the wastage can also be reduced.

\section{Methodology}

\subsection{Materials}

Oil Palm Frond (OPF) were supplied by Szetech Engineering Sdn Bhd which is shown in Figure 1. The fiber were crushed using a Low Speed Mini Granulator (Model: AA-150) to obtain fibers with smaller size. Then it was sieved by using a sieving machine to obtain a mesh size of $0.28 \mathrm{~mm}$. Urea Formaldehyde used as matrix was supplied by Hexzachem Sarawak Sdn Bhd which is shown in Figure 2. Urea Formaldehyde has a melting point approximately $30^{\circ} \mathrm{C}$.

\subsection{Fabrication of the Composite}

The OPF fiber and UF samples were weighed using a weighing machine to obtain two different fiber loading, which were $40 \%$ and $50 \%$ fiber. The size of the mold is $200 \times 200 \times 6 \mathrm{~mm}$. A targeted density of $0.7 \mathrm{~g} / \mathrm{cm} 3$ is used. By using the general formula of density where $\mathrm{m}$ is the mass of fiber and UF, and V is the volume of the mold, the mass of total fiber needed can be calculated. Table 1 shows the mass distribution of fiber and UF with different fiber loading. The total mass of the fiber and the UF is $140 \mathrm{~g}$. For $40 \%$ fiber loading, $56 \mathrm{~g}$ of fibers and $84 \mathrm{~g}$ of UF were used. While $50 \%$ fiber loading, $70 \mathrm{~g}$ of fiber and $70 \mathrm{~g}$ of UF were used. The fiber and UF sample were mixed together using a mechanical stirrer until homogenous. Grease were applied onto the mold for ease removal of the composite after fabrication. The mixture of fiber and UF were poured onto the mold and hand pressed to make it more compact. The mold was then placed into the hot press machine for hot press process. The composite was hot pressed for $1200 \mathrm{~s}$ at $175^{\circ} \mathrm{C}$, then cold pressed for $1200 \mathrm{~s}$ at $28^{\circ} \mathrm{C}$. Both hot and cold press were done under a pressure of $5 \mathrm{MPa}$. After the composite has formed, it was cut into several samples for flexural and tensile test. Prior to the testing, the samples were conditioned.

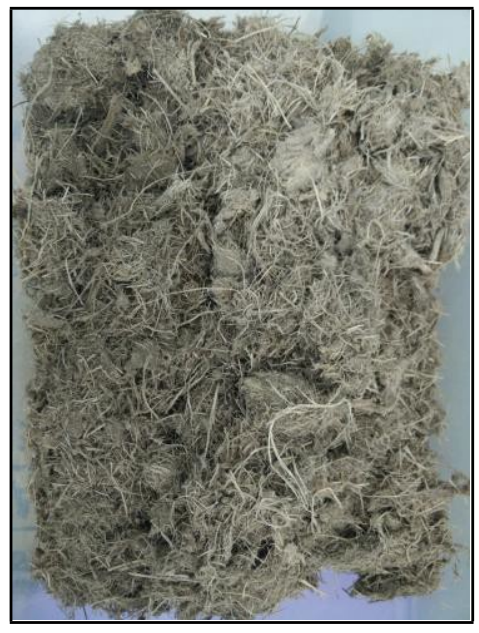

Fig. 1 - Oil palm frond fiber

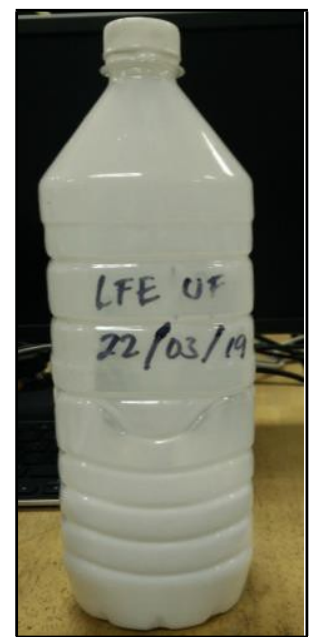

Fig. 2 - Urea formaldehyde 
Table 1 - Mass distribution of fiber and urea formaldehyde

\begin{tabular}{llll}
\hline Total & Wt\% of & \multicolumn{2}{c}{ Mass (g) } \\
\cline { 3 - 4 } Mass (g) & Fiber & Fiber & UF \\
\hline \multirow{2}{*}{140} & 40 & 56 & 84 \\
& 50 & 70 & 70 \\
\hline
\end{tabular}

\subsection{Mechanical testing}

In this study, the mechanical properties of OPF fiber and UF composite were tested. The fiber loading of 40 and 50 $\%$ were used for a fiber mesh size of $0.28 \mathrm{~mm}$.

For flexural test, Hegewald \& Peschke Universal Tensile Machine (UTM) 10kN was used. The schematic diagram of flexural test is shown in Figure 3. The dimension of the sample for flexural test is shown in Figure 4 with total length of support length $80 \mathrm{~mm}$. The composite were then cut into rectangular shape with dimension of $96 \times 20 \times 5 \mathrm{~mm}$. Before testing, the samples were conditioned at $23 \pm 2{ }^{\circ} \mathrm{C}$ and $50 \pm 5 \%$ relative humidilty for at least 40 hour. The flexural test was done based on the ASTM D-790 standard with crosshead speed of $2.13 \mathrm{~mm} / \mathrm{min}$.

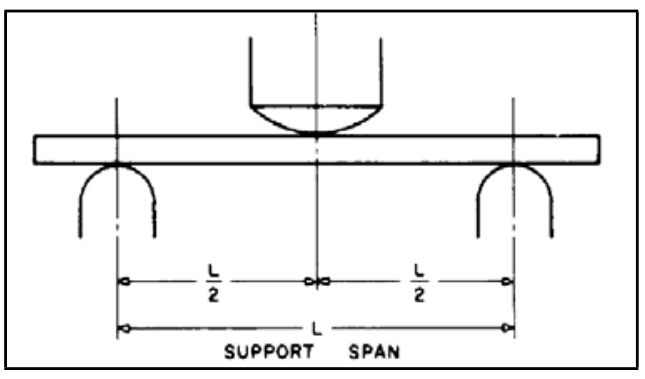

Fig. 3 - Sample for flexural test

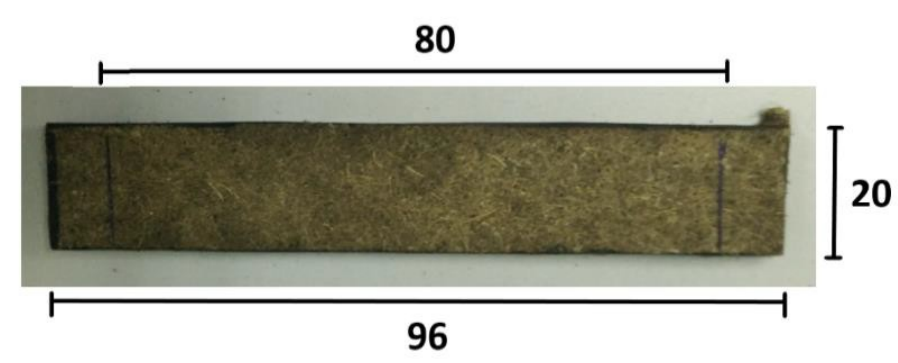

Fig. 4 - Flexural test sample dimension

For tensile test, the same UTM machine for flexural test was used. The samples were also conditioned prior to testing. The tensile test was done in accordance with ASTM D-638 standard. The samples were cut into dog-bone shape with a gauge length of $50 \mathrm{~mm}$. The setting of crosshead speed was $0.1 \mathrm{~mm} / \mathrm{min}$. For tensile test, 2 samples with 5 replicates were tested. The sample used for the tensile test is shown in Figure 5.

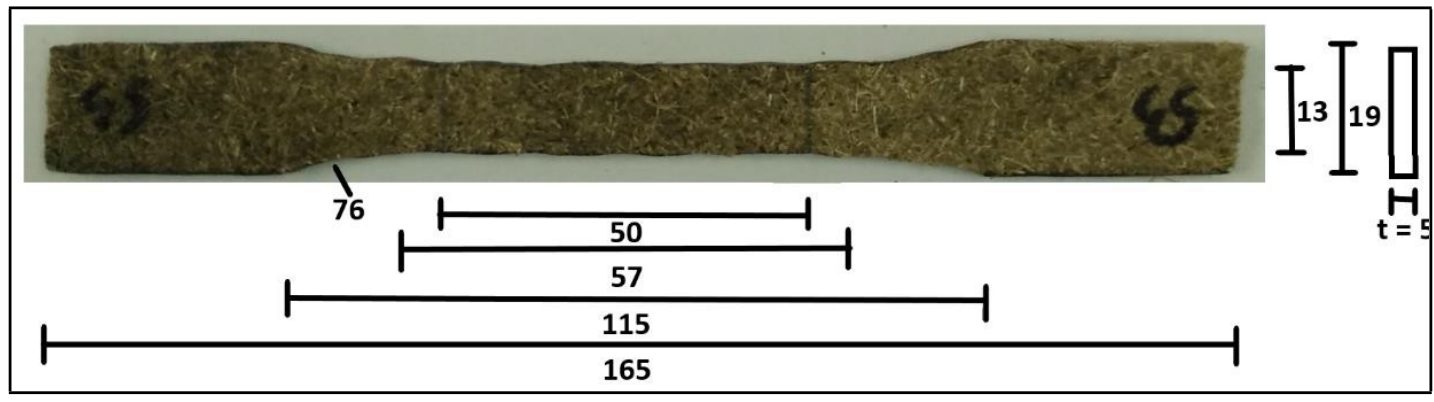

Fig. 5 - Dog bone sample for tensile test

\subsection{Morphological Observation}

Jeol JSM-6000 Plus, which is shown in Figure 6 was used to observe the morphology of OPF/UF composites. Prior to the observations, the composite was cut into smaller size and coated with a thin layer of gold by using the smart coater. The composites were observed using $10 \mathrm{kV}$ with magnification of 50. 


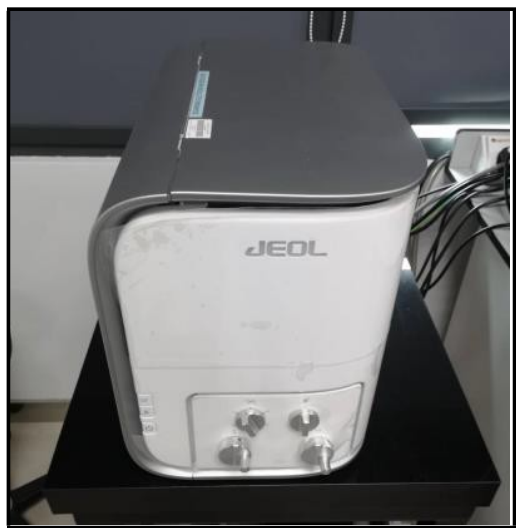

Fig. 6 - Scanning electron microscope (Joel JSM-6000 Plus)

\section{Results}

\subsection{Flexural and Tensile Strength of Composite}

In this study, the mechanical properties of two different fiber loading composites were evaluated. Figure 7 shows the comparison between flexural and tensile strength of the composite results. Based on flexural strength result, the composite with $40 \%$ fiber content have flexural strength of $1.396 \mathrm{MPa}$, whereas for the board with $50 \%$ fiber content, the flexural strength is $1.4306 \mathrm{MPa}$. Comparing both result, the composite with higher fiber content has higher flexural strength. In a studied done by Abdul Khalil et al. on recycled polypropylene and oil palm biomass has also reported that as the fiber loading increases, the flexural strength also increases [13]. Ojaswi Panda [14], which conducted a study on the effect of fiber parameters on the mechanical behaviour of bamboo-glass fiber reinforced epoxy based hybrid composites discovered that the samples or composite with higher loading of bamboo fiber to glass fiber gives better performance in terms of flexural strength. In another study [15], when the fibers in the medium density fiberboard increases, the flexural strength will increase too. However, in a separate study done by Azmi [16], the properties of composite decrease when the fiber content has reached its limit. When the fiber amount exceeded its limit, the interface will become weaker and it could also led to insufficient wetting.

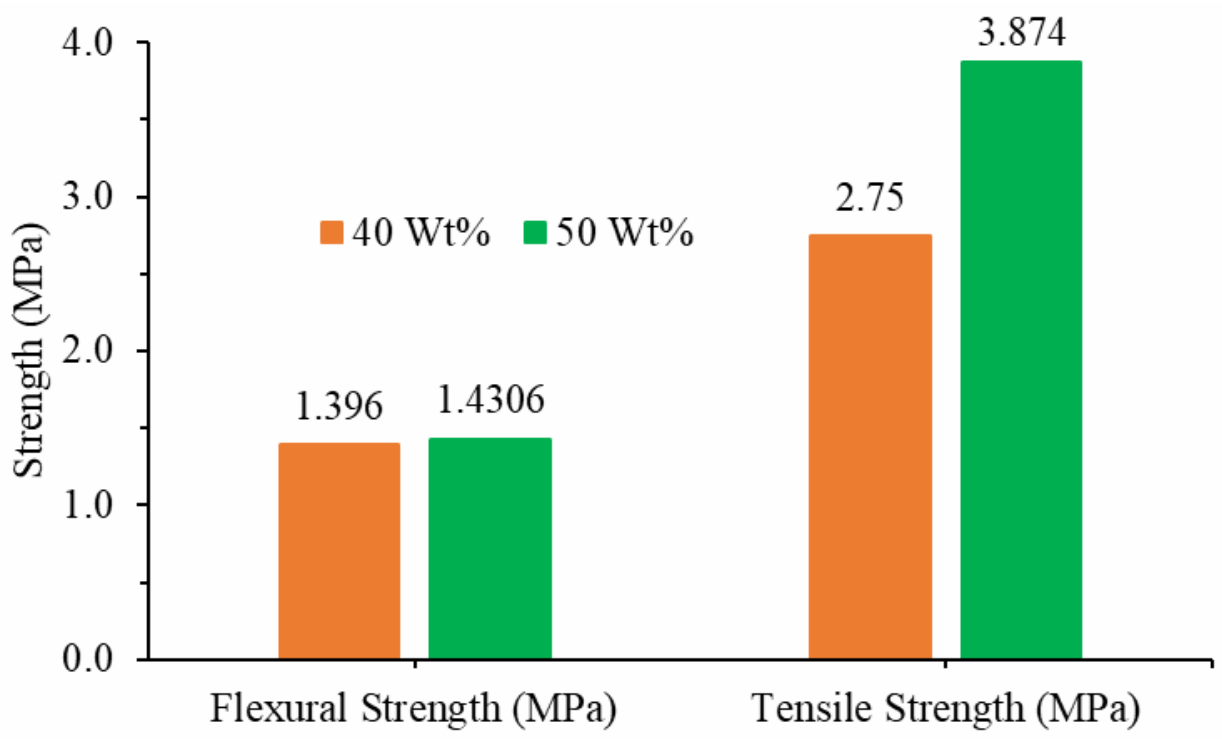

Fig. 7 - Flexural and tensile strength of composite with different fiber loadings (40wt\% and 50wt\%)

Based on the tensile strength result, the composite with $50 \%$ fiber content have higher tensile strength which is 3.874 MPa whereas the composite with $40 \%$ fiber content have lower strength which is $2.750 \mathrm{MPa}$. The same results were reported by Ojaswi Panda [14] who did comparison study on the effect of fiber loading to the tensile properties of bamboo fiber composite. This may be due to the stiffness of the fiber which contributes to the strength of composite. 
In this study, it was found that the strength is quite low. The low strength of the composite may be due to poor fiber dispersion or distribution during the fabrication process. When the fibers are not properly mix with the resin, it could affect the mechanical performance of the composite. During the tensile and flexural test, the stress does not distribute evenly, thus affect the strength [17]. The fibers which have irregular shape may also affect the properties as they may not be able to support the loading or stress applied to the matrix [18]. Based on previous study [19], the tensile strength of the composite depends on three factors which are the strength, the bonding strength effectiveness between the matrix and fiber during the stress distribution, and the modulus of fiber. There are three factors which will affect the mechanical properties of the composites, which are the size of fiber, fiber-matrix interface adhesion and the fiber loading [20]. The performance of the composite might also be affected by the hot press parameters. By using different heating time, cooling time and pressure applied to the mold, the results of the strength could varies.

During the flexural test, the modulus of elasticity (MOE) of the samples were also recorded. The value of the modulus of elasticity is presented in Figure 8 . Based on the MOE values obtained from the flexural test, it can be observed that the MOE for composite with $40 \%$ of fiber content is $640.2464 \mathrm{MPa}$. While for composite with $50 \%$ of fiber content, the MOE value is 1248.9516 . Based on the results, we can conclude that the MOE values for $50 \%$ fiber content is almost two times higher than composite with $40 \%$ fiber content. As the fiber content increase, the MOE value also increase.

Rozman et al. performed studies on different filler loading for empty fruit bunch/polyethylene (EFB/PE) found that the MOE increases as the percentage of filler increase. However, once its reached a certain percentage of filler, the MOE will drop [21]. In another study [15], when the fiber loading which is the coconut coir increases, the MOE value increases. This was also due to the stiffness of the fiber which then contributes to the value of MOE.

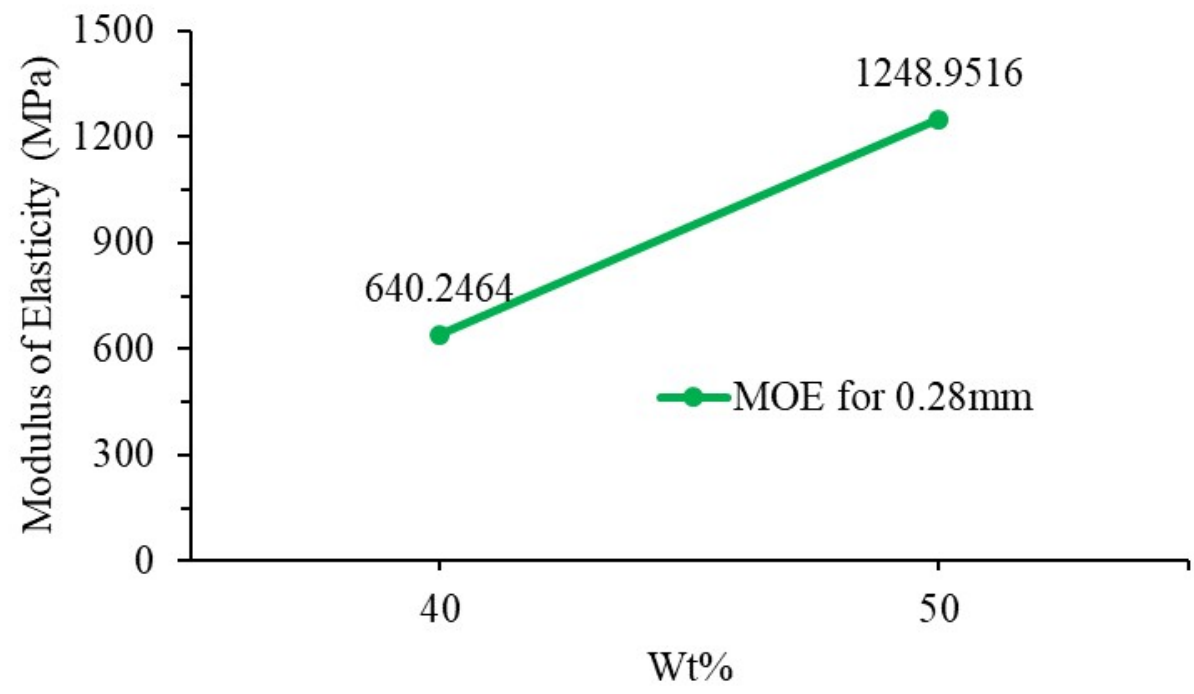

Fig. 8 - Modulus of elasticity of composite with 40wt\% and 50wt\% of OPF Fiber

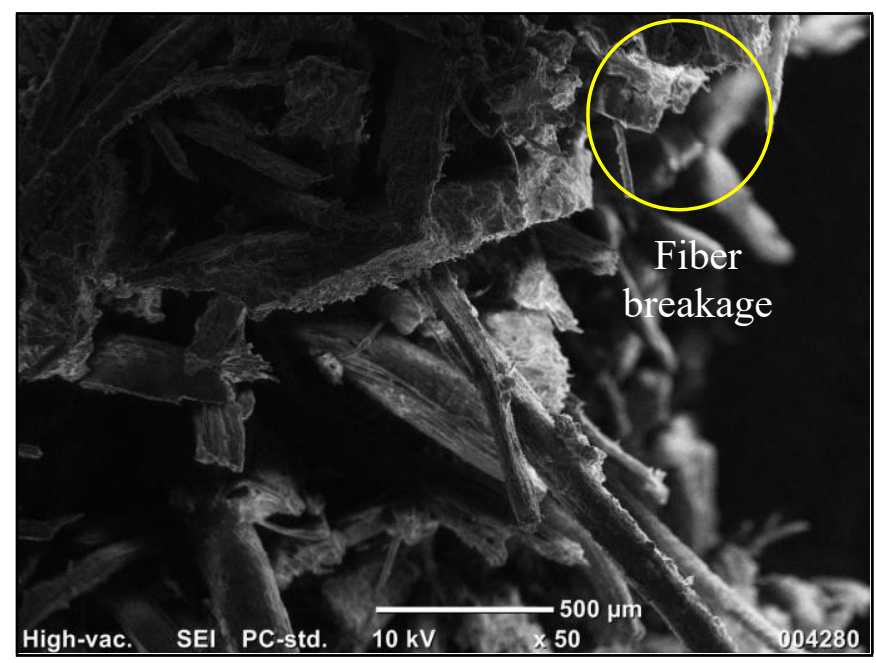

Fig. 9 - Composite with $40 w t \%$ of OPF fiber 


\subsection{Morphology}

All the broken composites after tensile test were observed in the SEM. It showed that fiber breakage, voids and holes were observed from the SEM pictures shown in Figure 9 and Figure 10. From the morphology, it was found that fiber breakage or pullout occurs. This may be due to the mixing process of the fiber and UF. When the UF and fiber does not mix homogenously, fiber breakage or pullout can occur. It was stated in a study done by Anuar et al. on comparison of the morphological and mechanical properties of oil palm fibers and kenaf fibers in nonwoven reinforced composites, insufficient wetting between the fibers and matrix can affect the strength of the composite [22].. Studied done by Chern et al. on methacrylate silane treated oil palm mesocarp fiber reinforced biodegradable hybrid composites, there are no fiber pullout or cavity present in the silane treated oil palm mesocarp fiber [23]. In this study, the fiber used were not treated, thus this one factor that may contribute to low mechanical properties of composites that lead to fiber breakage.

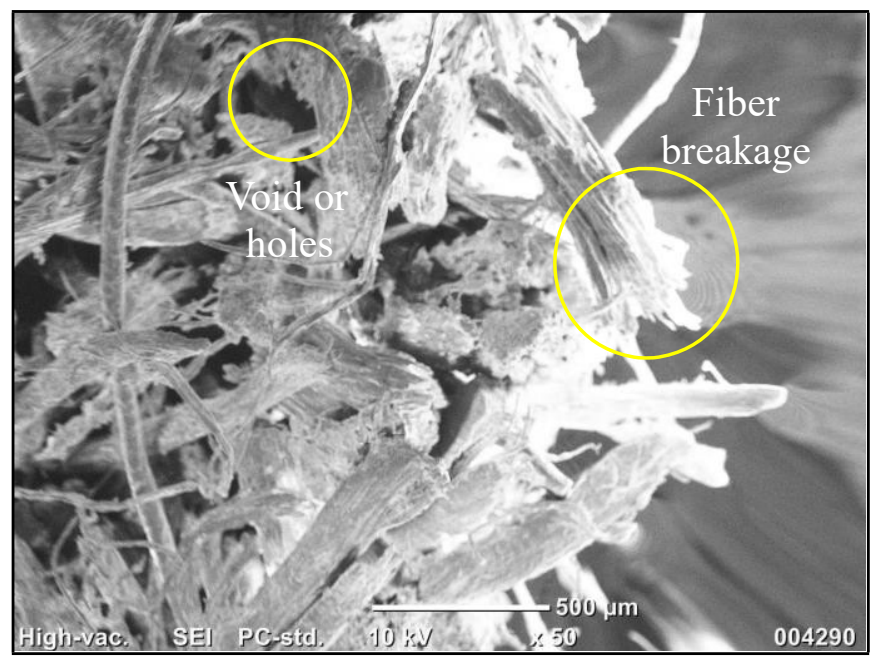

Fig. 10 - Composite with 50wt\% of OPF fiber

\section{Conclusion}

In this study, the effect of different fiber loading with $0.28 \mathrm{~mm}$ mesh size OPF fiber and urea formaldehyde were studied. From the study, it was concluded that the amount of fiber loading is crucial to produce a composite with high mechanical properties. After comparison between the two fiber loading, it is concluded that the composite with $50 \%$ fiber loading have better mechanical properties. The highest flexural and tensile strength that can be achieved were $1.4306 \mathrm{MPa}$ and $3.874 \mathrm{MPa}$ respectively. However, the performance of the composite were expected to drop once its reached a certain loading.

\section{References}

[1] Sapuan, S. M. (2017). Composite Materials, in Composite Materials - Concurrent Engineering Approach (pp. 57-93). Elsevier Inc.

[2] Biron, M. (2018). Outline of the Actual Situation of Plastics Compared to Conventional Materials, in Thermoplastics and Thermoplastic Composites (Third Edition) (pp. 1-30). Elsevier Ltd.

[3] Dutta, T., Barman, A. \& Majumdar, G. (2019). Green and Sustainable Manufacturing of Metallic, Ceramic and Composite Materials, Encyclopedia of Renewable and Sustainable Materials (pp. 1-13).

[4] Tanzi, M. C., Farè, S. \& Candiani, G. (2019). Mechanical Properties of Materials, in Foundations of Biomaterials Engineering (pp. 105-136). Elsevier Ltd.

[5] AL-Oqla, F. M. \& Salit, M. S. (2017). Natural fiber composites, in Materials Selection for Natural Fiber Composites (pp. 23-48). Elsevier Ltd.

[6] Khalil, H. A., Jawaid, M., Hassan, A., Paridah, M. and Zaidon, A. (2012). Oil Palm Biomass Fibres and Recent Advancement in Oil Palm Biomass Fibres Based Hybrid Biocomposites, in Composites and Their Applications (pp. 187-220). InTech.

[7] Sarikaya, E., Çallioğlu, H. and Demirel, H. (2019). Production of epoxy composites reinforced by different natural fibers and their mechanical properties, Composites Part B.

[8] Verma, D. \& Senal, I. (2019). Natural fiber-reinforced polymer composites: Feasibility study for sustainable 
automotive industries, in Biomass, Biopolymer-Based Materials, and Bioenergy (pp. 103-122). Woodhead Publishing Series in Composites Science and Engineering.

[9] Saba, N., Jawaid, M. \& Sultan, M. (2017). Thermal properties of oil palm biomass based composites, in Composite Materials - Processing, Properties and Applications (pp. 95-122).

[10] Abdul Khalil, H. P. S., Siti Alwani, M., Ridzuan, R., Kamarudin, H. \& Khairul, A. (2008). Chemical Composition, Morphological Characteristics, and Cell Wall Structure of Malaysian Oil Palm Fibers, PolymerPlastics Technology and Engineering (pp. 273-280).

[11] Hassan, S., Kee, L. S. \& Al-Kayiem, H. H. (2013). Experimental Study of Palm Oil Mill Effluent and Oil Palm Frond Waste Mixture as an Alternative Biomass Fuel," Journal of Engineering Science and Technology (pp. 703-712).

[12] Khalil, H. A., Dungani, R., Hossain, M., Suraya, N., Aprilia, S., Astimar, A., Hayawin, Z. N. \& Davoudpour, Y. (2015). 15 - Mechanical properties of oil palm biocomposites enhanced with micro to nanobiofillers, in Biocomposites: Design and Mechanical Performance (pp. 401-435). Woodhead Publishing Series in Composites Science and Engineering.

[13] Khalil, H. P. S. A., Poh, B. T., Issam, A. M. \& Jawaid, M. (2010). Recycled Polypropylene - Oil Palm Biomass: The Effect on Mechanical and Physical Properties, Journal of Reinforced Plastics and Composites (pp. 11171130).

[14] Panda, O. (2012). A study on the effect of fiber parameters on the mechanical behavior of bamboo-glass fiber reinforced epoxy based hybrid composites, Rourkela.

[15] Mahzan, S., Ahmad Zaidi, A., Ghazali, M., Arsat, N., \& M. Hatta, M. (2010). Mechanical Properties of Medium Density Fibreboard Composites Material Using Recycled Rubber and Coconut Coir. International Journal of Integrated Engineering, 2(1).

[16] Azmi, M. A. (2012). Rigid Polyurethane Foam Reinforced Coconut Coir Fiber Properties. International Journal of Integrated Engineering, 4(1).

[17] Rasat, M. S. M., Wahab, R., Sulaiman, O., Moktar, J., Mohamed, A., Tabet, T. A. \& Khalid, I. (2011). Properties of Composite Boards from Oil Palm Frond Agriculture Waste, BioResources (pp. 4389-4403).

[18] Chee, P. E., Talib, R. A., Yusof, Y. A., Chin, N. L., Ratnam, C. T., Khalid, M. \& Chuah, T. G. (2010). Mechanical and Physical Properties of Oil Palm Derived Cellulose-LDPE Biocomposites as Packaging Material, International Journal of Engineering and Technology (pp. 26-32).

[19] Ismail, A. E., Khalid, S. N. A., Zainulabidin, M. H., Tajul Arifin, A. M., Hassasn, M. F., Ibrahim, M. R., \& Rahim, M. Z. (2018). Mechanical Performances of Twill Kenaf Woven Fiber Reinforced Polyester Composites. International Journal of Integrated Engineering, 10(4).

[20] Khalil, H. A., Dungani, R., Hossain, M., Suraya, N., Aprilia, S., Astimar, A., Hayawin, Z. N. and Davoudpour, Y. (2015). Mechanical properties of oil palm biocomposites enhanced with micro to nanobiofillers, in Biocomposites: Design and Mechanical Performance (pp. 401-435).

[21] Rozman, H. D., Ismail, H., Jaffri, R. M., Aminullah, A. \& Ishak, Z. A. M. (1998). Mechanical Properties of Polyethylene Oil Palm Empty Fruit Bunch Composites, Polyme, Plastics Technology and Engineering, vol. 37, no. 4 (pp. 495-507).

[22] Anuar, N. I., Zakaria, S., Gan, S., Chia, C. H., Wang, C. \& Harun, J. (2019) Comparison of the morphological and mechanical properties of oil palm fibres and kenaf fibres in nonwoven reinforced composites, Industrial Crops \& Products (pp. 55-65).

[23] Eng, C. C., Ibrahim, N. A., Zainuddin, N., Ariffin, H. \& Yunus, W. M. Z. W. (2014). Impact Strength and Flexural Properties Enhancement of Methacrylate Silane Treated Oil Palm Mesocarp Fiber Reinforced Biodegrable Hybrid Composites, The Scientific World Journal 8. 